\title{
Process mapping and scripting in the Accounting Information Systems (AIS) curriculum
}

\author{
ROBERTA ANN JONES* and KATHRYN A.S. LANCASTER
}

California Polytechnic State University, USA

Received: August 2000

Revised: May 2001

Accepted: August 2001

\begin{abstract}
The ability to understand, document, and suggest improvements for a business process is an important skill for an accounting student for the following reasons: (1) efficient business processes give businesses a competitive advantage; (2) business process analysis provides auditors with an assessment of business risk; and (3) successful enterprise resource planning implementation depends on understanding and improving existing business processes. It is suggested that students be introduced to process mapping and scripting in an accounting information systems (AIS) course to facilitate their understanding of business processes and help them visualize the interaction between functional areas. The specifics of process mapping are covered and advantages of incorporating process mapping into the AIS curriculum discussed. It is also proposed that scripting, which is used to facilitate configuration, testing of ERP software and communication between the accountant and the programmer, be included in the AIS course. Finally, suggestions for classroom activities are included.
\end{abstract}

Keywords: business processes, process mapping, scripting, AIS education, AIS curriculum

\section{Introduction}

During the development of a Masters in Accounting programme and three distinct undergraduate accounting concentrations (based on career opportunities) our Accounting Department's Advisory Board (which includes industry representatives as well as individuals from both international ${ }^{1}$ and regional professional services firms) was involved in curriculum changes. The Board members recommended inclusion of business process analysis and exposure to an Enterprise Resource Planning (ERP) application ${ }^{2}$ in our curriculum. On this advice, the authors began to research what to include in such a class. Course syllabi were collected and several individuals were consulted, both educators and practitioners, in an effort to determine course content. During the discovery process, one of the authors spoke with a manager at one of the international accounting firms. It was during this conversation that the use of process mapping and scripting first came to our attention.

* Address for correspondence: Dr. R.A. Jones, Associate Professor of Accounting, California Polytechnic State University, San Luis Obispo, CA 93407, USA. E-mail: roajones@calpoly.edu

'Because the number of 'Big XX' professional services firms keeps changing in recent years and because they all have an international presence at this time, we choose 10 refer 10 these professional services firms as 'international firms.'

${ }^{2}$ A true ERP system has one inlegrated and shared database that collecis and provides information from all areas in a company. 
Further research indicated that process maps have widespread acceptance. We have developed a senior-level course that utilizes process maps and scripts to teach business processes and its relationship to understanding ERP systems. Further, we believe these tools could be successfully incorporated in an introductory Accounting Information Systems (AIS) course.

Similar to flowcharts and data-flow-diagrams (DFD), process maps provide a visual representation of a process and the preparation and disposition of documents that flow through that process. Process maps are simple models of the complex processes inherent in large firms. The relative ease of building simple, yet complete, models of complex systems may explain the acceptance of process mapping for understanding and documenting such systems by practitioners and consultants. For example, many auditors now map business processes during the attestation process in order to better evaluate business risk, and AIS experts use process mapping to facilitate an ERP implementation. Carr and Johansson (1995) describe the use of process mapping during process re-engineering in order to fully understand the current state (as is) and facilitate adoption of an improved process (to be). Scripting is used to communicate the information systems aspect of the improved process to programmers, and for testing a new software implementation.

Given its current acceptance, it is important that accounting students fully appreciate the concept of mapping business processes. It was found that, while most students are introduced to flowcharts, DFD, and McCarthy's (1982) REA (resource, events and agents) model in an AIS course, to date, very few are exposed to process mapping tools. Anyone who has lectured on transaction cycles (a.k.a. business processes) knows that this material can be dry, boring and appear obvious to the student. Use of modelling tools, such as process mapping and scripting, can make learning business processes more interesting and interactive. It is suggested that students be introduced to both tools in an AIS class not only so they understand the tool, but as a method to help them understand and document business processes. $^{3}$

The rest of this paper is organized as follows: first is provided a summary of the few papers that discuss the history and use of process mapping and scripting. Next is presented the specifics of process mapping and scripting, and it is shown how these tools are used to identify internal control weaknesses as a step in process redesign. Third, is described how these tools have been used in a traditional AIS course. Fourth, a plan is presented for using these tools in a senior-level business process course in which students will learn by doing small process maps and scripts. Finally, is presented a summary and conclusions.

\section{Literature review}

Independent of accountants and auditors, business managers began to use the term 'business processes' to describe what accountants refer to as transaction cycles as they worked to make their operations more efficient. Software programmers, attempting to understand business systems in order to develop an integrated information system (now known as ERP) adopted the term. Though the two terms, business processes and transaction cycles, are similar, the term business processes has gained widespread acceptance and use outside of accounting and auditing; far more so than the term transaction cycles. To illustrate the

${ }^{3}$ Our faculty advisory board also made it clear that if there were too much material to cover in one quarter they would prefer to cut some ERP content from the course rather than cut any of the process mapping exercises. 
widespread acceptance of the term 'business process,' one of the authors conducted a search on Amazon.com. The result was a list of 643 books with 'Business Process' in the title versus one book with 'Transaction Cycle.'

In an effort to gain a competitive advantage, businesses often engage consultants (and/or entrust an in-house team) to document, understand, and optimize their business processes. For instance, Arthur Andersen has created a 'Global Best Practices' division, which performs 'best practice' audits for companies to identify areas for improvement (Hiebeler et al., 1998). The authors found that a common feature of companies implementing best practices is that they take a strong process view of their company. The process approach cuts across internal functional boundaries, which allows managers to view their company from a holistic perspective. By examining and mapping each business process, a process reengineering team is better able to identify areas where improvements are possible (Hiebeler et al., 1998, pp. 27-28).

In a similar fashion, AIS experts incorporate process mapping during process engineering in order to understand current business processes and strategize on improvements, particularly when implementing enterprise management systems such as Oracle's e-business suite $^{4}$ or SAP's R/3 System. In their discussion of a successful Oracle Financial implementation, James and Seibert (1999) believe that understanding how a business operates is paramount. They recommend modelling the entire business, which requires the installation team to describe the operation and define all the interactions within the company and between suppliers and customers. Part of this modelling is accomplished with process maps.

The international professional services firms now include a business process analysis as part of their assurance services to assess business risk and to help them understand, audit and suggest business processes improvements. For example, KPMG implemented a Business Measurement Process (BMP) audit, which is a 'risk-based strategic-systems auditing approach' (Bell et al., 1997, p. 2). The BMP framework is a holistic approach that includes evaluating a company based on external forces and the company's (1) strategy, (2) occupied niches, (3) business and financial relationships, and (4) internal business processes. By mapping and analysing a company's business processes as part of the BMP audit, the auditor is able to identify weak process links and/or internal control deficiencies.

In a true ERP system, there is one integrated database that is used by everyone in the company. The right information must be available to the appropriate people and restricted from those without authority. Consequently, access must be controlled and configured into the system. For example, in most companies, restrictions are placed on payroll records to limit access. These restrictions are handled by limiting form and/or account access. As William R. Kinney, Jr. points out in the preface to Auditing Organizations Through a Strategic Systems Lens (Bell et al., 1997, p. v), 'controls over transactions are increasingly embedded in software.' Process mapping can help determine which controls need to be embedded in the software and which risks are mitigated by physical controls.

The earliest reference to process mapping we found was in Harrington's (1991) book on business process improvement. One illustration, while it is referred to as a 'Functional Flowchart,' clearly resembles a process map in that activities/operations and decision points are laid out on a functional grid (p. 103). Carr and Johansson (1995), writing for Coopers \& Lybrand Center of Excellence for Total Quality and Change Management, refer

${ }^{4}$ Formally known as Oracle Applications. 
to 'mapping the Core Business Process' and illustrate what is clearly a process map rather than a flowchart (p. 140).

There are a number of papers that discuss process mapping. For example, Symons and Jacobs (1997) describe and illustrate a form of process map for use in a quality improvement programme; Wisner and Roth (1998) describe and illustrate process maps as an aid for activity based costing. Other examples of its widespread acceptance and use include a Farmers Insurance report of the use of process maps by their Internal audit staff (Keller and Jacka, 1999) and Aldowaisan and Gaafer's (1999) application of linear programming techniques to process mapping. Selander and Cross (1999) refer to process mapping as flowcharting, while clearly illustrating a process map rather than a flowchart. Informal discussions with representatives of several of the international firms confirmed that process mapping is being used as part of the analysts' attempts to understand complex processes. Based on evidence that process mapping is used in so many areas, the present authors conclude that process mapping has become a necessary element in the accountant's skill set and that accounting students would benefit by learning how to map a business process.

An additional tool being utilized by AIS consultants is called Scripting. When a consultant redesigns a system, often two process maps are prepared. The first map, the 'as is' map, provides a visual image of the existing system. The second map, the 'to be' map, provides a visual image of the redesigned system. Scripting is used to communicate the accountant's plan as incorporated in the 'to be' process map to the programmer and to facilitate configuration and testing of the ERP software. Scripting can include providing screen shots, detailed field data, and transaction test data for a specific implementation of an ERP.

Accounting information systems (AIS) textbooks have, for some time, included flowcharting, dataflow diagrams, and REA modelling as tools used by accountants for understanding business systems. See, for example, Heagy et al. (1999), Hall (2000), Hollander et al. (2000), Romney and Steinbart (2000), and Wilkinson et al. (2000). While these topics continue to be important and should not be excluded from the curriculum, academia has fallen behind the practitioner in this area because process mapping is not currently included in any of the AIS textbooks. This absence is an indicator of the probable absence of process mapping and scripting from the AIS curriculum. ${ }^{5}$

\section{Process mapping and scripting}

In this section is detailed the specifics of how to draw a process map including the conventions of process mapping as detailed in The Basics of Process Mapping by $\mathrm{R}$. Damelio (1996) and variations used by the international firms (Fulscher and Powell, 1999). One example of a variation is KPMG's Business Measurement Process, which provides a business model designed to help the auditor better evaluate audit risk and suggest potential improvement opportunities to the client (Bell et al., 1997). Also a small script is described and illustrated that is prepared by accountants for use by programmers and other technical people in the configuration of ERP software and used by functional people for testing the software.

\footnotetext{
${ }^{5}$ Inclusion in AIS textbooks is an imperfect indicator of the AIS curriculum.
} 


\section{Process mapping}

According to Damelio (1996) standard process mapping conventions include the following:

1. The map is laid out horizontally with functional areas listed down the left hand side of the map.

2. Functional areas are separated with a solid line.

3. Subfunctions within an area are separated with a broken line.

4. Only two symbols are used: the rectangle, which represents a process; and the diamond, which represents a decision.

5. Lines with arrow heads connecting the symbols must be labelled with the document(s) that flow through the process except for lines coming out of decision diamonds, which are labelled with 'yes' or 'no' (the document is understood to be passing through the decision symbol.) Documents can include either hard-copy or electronic documents.

6. Each process rectangle should describe a process, not a document.

7. The map should follow a general left to right, top to bottom configuration.

The above might be considered 'pure' process mapping. The international firms have modified these conventions slightly. For example, PricewaterhouseCoopers includes a 'stop' symbol and 'hats' that are used to detail which software application is being used for the particular process (Access, Excel, SAP . . .). PricewaterhouseCoopers tends not to label their arrows with the document. Coopers and Lybrand, ${ }^{6}$ on the other hand, follow the conventions except for the solid line between functions (see Fulscher and Powell, 1999). KPMG also does not delineate between functional areas and records processes sequentially in a left to right, top to bottom format (Bell et al., 1997). A simple example of a process map depicting a sales order is provided in Figure 1. To facilitate comparison, Figure 2 depicts the same process using flowcharting conventions. These two figures are provided to illustrate the differences between flowcharting and process mapping. ${ }^{7}$ Note the process map is simpler, uses fewer symbols and has a horizontal layout and identifies the interaction between functional areas. The basis of a process map is the workflow and associated decision points, whereas the focus of a flowchart is on the documents and details of the system.

\section{Scripting}

Once a revised system ${ }^{8}$ is developed during a software implementation, a script is developed by the accountant to provide the programmers with the information they need to configure the software according to the plan. ${ }^{9}$ While there appears to be no extant scripting conventions, per se, an examination of various scripts indicate that scripts should probably include the following:

${ }^{6}$ The PriceWaterhouseCoopers merger had not yet occurred when the cited paper was published.

7 This is not to suggest that either flowcharting or process mapping is superior, only that they are different; thus teaching flowcharting is not a substitute for teaching process mapping.

${ }^{8}$ Unless a firm is a start-up with absolutely no system currently in place, a software implementation will always be a revision of the current system which may be a manual system or a system using different software.

${ }^{9}$ For the nonfinancial areas of an ERP install, people from the functional area (marketing, human resources, production, shipping, etc.) would be involved. 


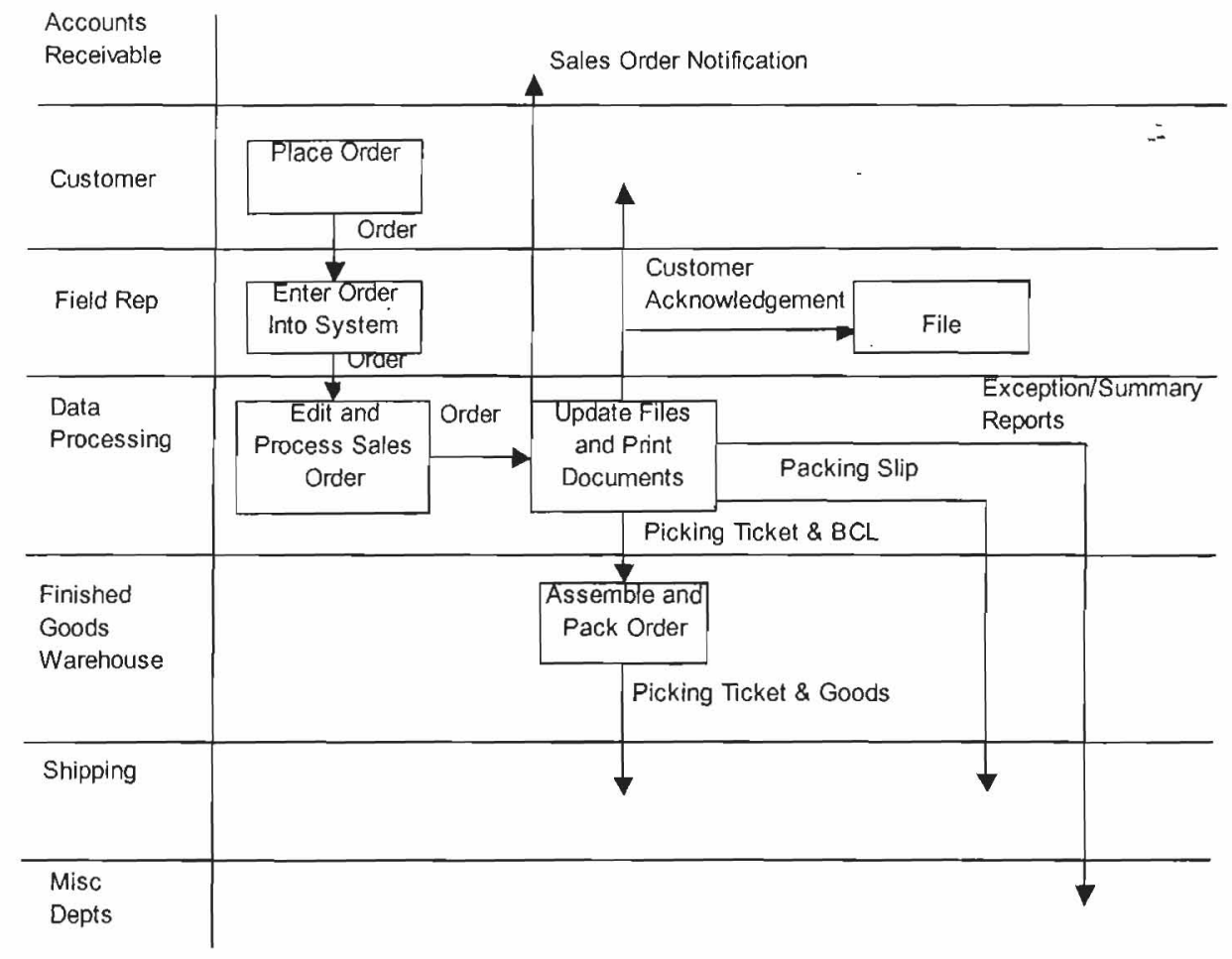

This map depicts a customer order being placed and entered by a Field Sales Rep into the system. The files are updated, the order is packed and shipped to the customer. Functional areas affected include Accounts Receivable, Customer, Field Sales Representative, Data Processing, The Finished Goods Warehouse, Shipping and Various Miscellaneous Departments.

Fig. 1. Process map.

1. Applicable screen shots.

2. The path to the screen within the software.

3. Detailed data for each field on the screen. The detailed data specified for a field can include:

(a) Whether the field is required or optional.

(b) Allowable characters (numeric, alpha, or both).

(c) Appropriate range of characters and/or entries.

(d) Look-up tables for filling the field.

(e) Links between the field and other fields.

4. Scripts can also include test transactions, with anticipated results, to ensure the system is working correctly once configured.

Figure 3 provides an example of a script to operationalize the order entry activity that is depicted in Figure 1 and Figure 2 as a single symbol in each of those models. Even though Figure 3 illustrates a very small script, several things can be inferred. First, an individual must be very familiar with a process and its relationships to other processes in order to build a quality script. Second, one can expect a lot of variation in script-building 


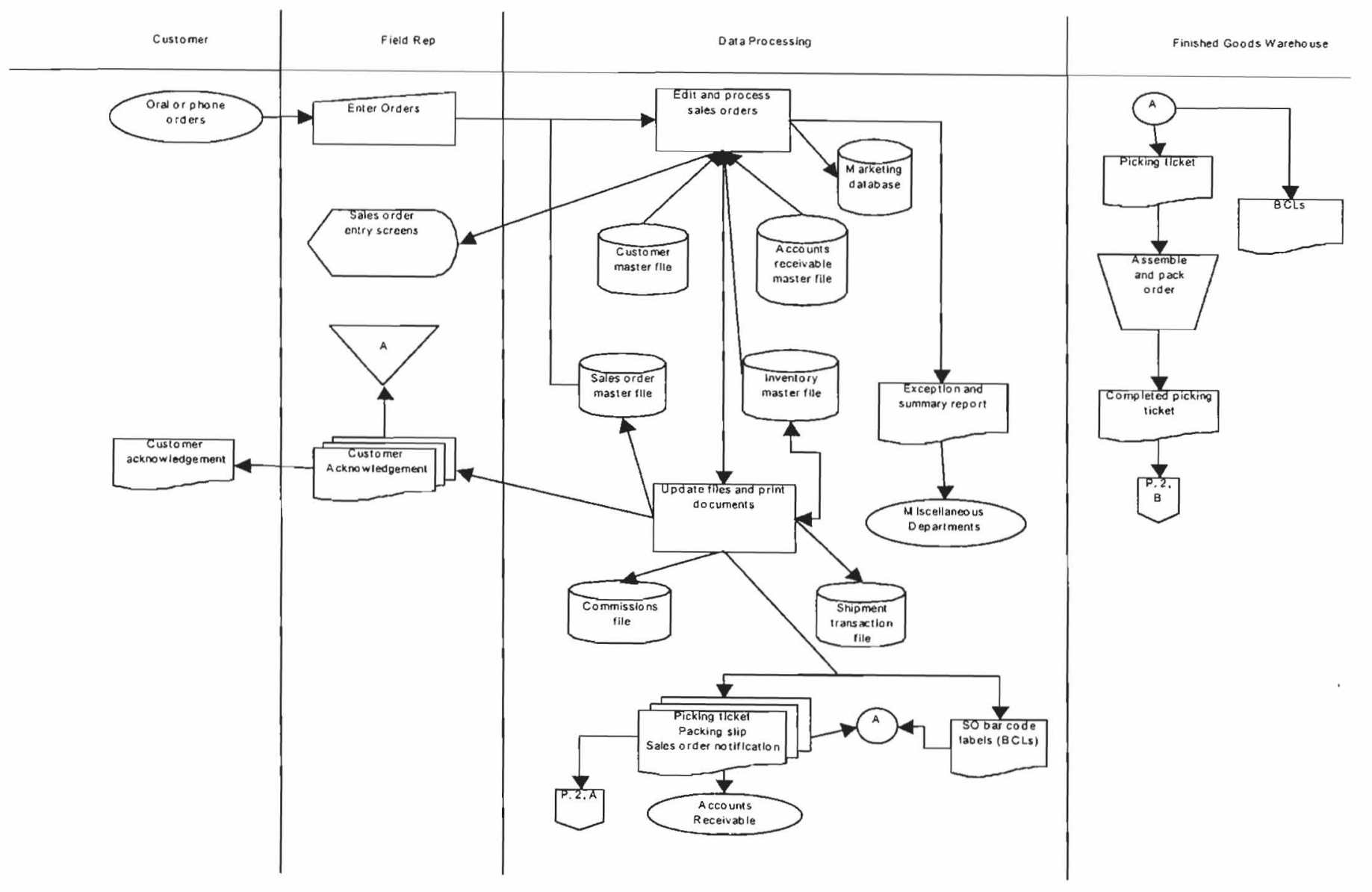

This flowchart depicts the same system depicted in Figure 1.

Fig. 2. Flowchart. 
Navigation:

1) Client Billing

2) Order Entry

3) Click "+"

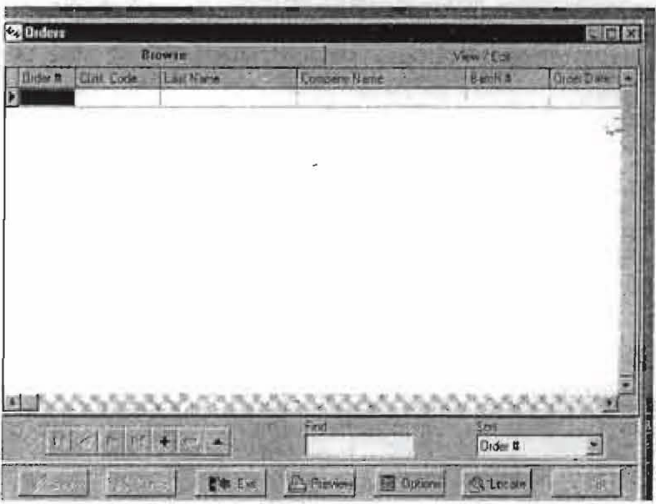

4) An Order is made up of beader and detail fields. The header fields are filled in as follows:

5) Batch Number: Use to print edit reports by batch number for editing purposes.

6) Order Date: Default to the current system date.

7) Memo/Desc: Allow Entry of a brief remark in this field. Print on the invoice header and copy to the Memo/Desc field of the A/R bill.

8) Customer code: Enforce entry of a valid customer code. Use List to show a list of customer codes, to choose a code or to add a new code.

9) Agency code: Default to the agency code in the customer record. Use List to show a list of agency codes, to choose a code or to add a new one.

10) Terms: Default to the payment terms in the customer record. Use List to show a list of payment terms, choose a term or to add a new one.

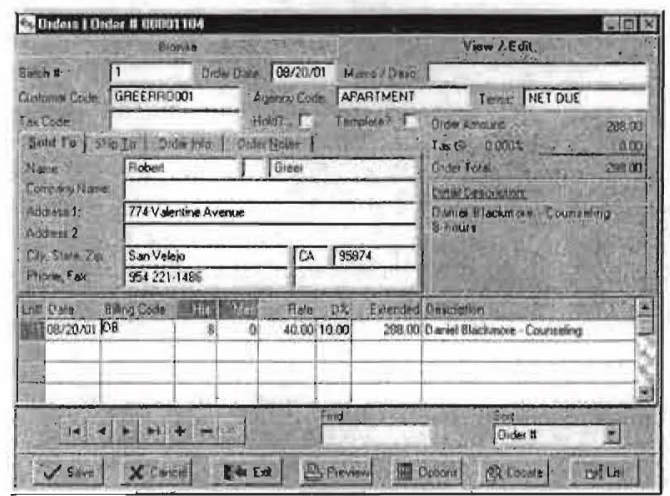

11) Tax Code: Default to the tax code from the customer record. Allow clanges if the change is a valid tax code. Use List to show a list of tax codes, choose a code or to add a new one.

12) Hold?: A Click here indicates the order will not be invoiced. Default from the payment terms.

13) Template?: A Click here indicates this order will be a template for quickly adding other similar orders in the future. A template order cannot be invoiced. Copies will be made using the Copy This Order menu option from the Options button.

14) Sold To/Ship To Address tabs: These addresses default from the customer record. Allow modification as necessary.

Fig. 3. Script example for subprocess: enter order into system.

among individuals without necessarily a great deal of variation in script content. Third, there is distinctly different information found in process maps and scripts. Finally, a script for even a small subprocess can be quite lengthy and detailed. ${ }^{10}$ Note that scripts can be used for implementation of software, testing of software and then documentation of the software as it is implemented.

${ }^{10}$ In fact, scripts are often 4 to 8 pages long for even a very small subprocess. The choice of the script for this paper was based solely on number of pages to take up in this article. To provide scripts for the entire process mapped and flowcharted in Figures 1 and 2, for example, would have required a minimum of 6 scripts and 12 pages. We were unable to identify a one-page script that provided meaningful information to two anonymous reviewers. 
15) Order Info tab: This tab will enable the following to be recorded:

- Discount: Default to the discount code in the customer record, if any.

- P.O. \#: Default to the purchase order number in the customer record, if any.

- Payment Ref. \#: Payment information can be entered for (E.G., a credit card approval).

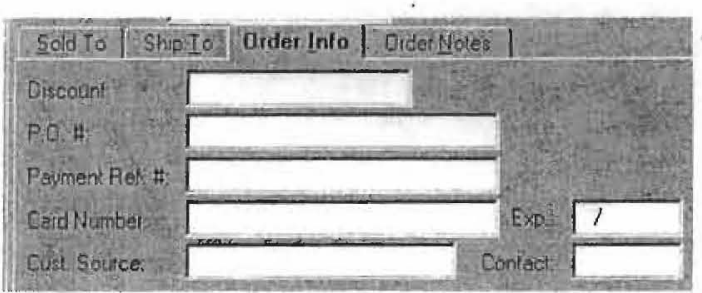

- Card Number: Record a credit card number here.

- Exp.: Record the credit card expiration date (MM/YY) here.

- Cust. Source: Defaults from the customer record. Use List to show a list of customer source codes, choose a code or to add a new one. This is used to track customer sources; how they heard of the product or service (e.g., newspaper, referral, etc.)

- Contact: Default to the contact code from the customer record. If there is no contact code in the customer record, default to the User $\mathrm{DD}$, assuming the User ID has been set up as a valid contact code. Use List to show a list of contact codes, choose a code, or to add a new one.

16) Order Notes tab: This note will print at the bottom of the invoice. Default from the company profile. Allow modification to this note by clicking on this tab for the current order.

The next fields are the order detail fields. These fields describe what the customer ordered

17) Ln\#: This is the detail line number. To be auto-generated; no changes allowed.

18) Date: Default to the current system date.

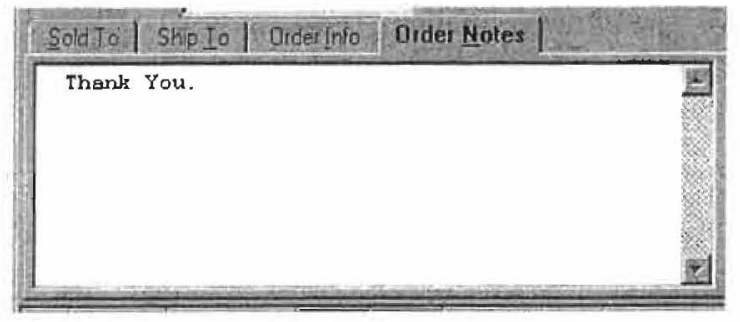
Allow changes

19) Billing Code: Enforce entry of a valid bill code. Use List to show a list of bill codes, choose a code or to add a new code.

20) Quantity: User will enter the quantity of service provided in the user-defined unit for that service (e.g. hours, days, etc.) The user-defined unit of measure is shown above this field.

21) Sub-Quantity: User will enter the sub-quantity of service provided in the user-defined sub-unit for that service (e.g., minutes, etc.). The user-defined sub-unit of measure is shown above this field.

22) Rate: Default to the rate from the billing code record.

23) $\mathrm{D} \%$ : Default to the greater of the discount from the billing code record or the discount from the discount code record. Allow modifications using a discount from 1 to 99 per cent.

24) Extended: This amount will be calculated by the software. No modifications allowed.

25) Description: Default to the Billing Text from the Billing code record. This can be modified by the user.

Fig. 3. (cont.)

\section{Process mapping in a traditional AIS course}

In a traditional AIS course flowcharting is usually introduced to the students with one or more flowchart projects assigned. Also, typically a few weeks are devoted to covering transaction cycles. As an experiment in developing the course discussed in the next section, a traditional AIS course ${ }^{11}$ was modified to include process mapping rather than flowcharting and more extensive coverage of business processes.

Students were assigned to read the textbook ${ }^{12}$ material covering flowcharting but no lecture time or projects was devoted to flowcharting. Instead, the standard process mapping

$"$ Actually, two courses were modified in the same way: a graduate course and an undergraduate course. The material presented was the same, the problems worked were the same in the two classes as well. The only difference was the final process mapping project for the graduate students was more complex than the undergraduate project.

${ }_{12}$ The undergraduate text used was Heagy et al. (1999), the graduate text used was Romney and Steinbart (2000). 
conventions were provided to the students both as a handout and during one class-period lecture. Several small process maps were developed in class during a second lecture. Students were informed of the use of process mapping by practitioners and it was emphasized in lectures and on the syllabus that a major process map project would be required at the end of the semester.

In the first examination, students were asked to map and flowchart the same process (similar to Figures 1 and 2). Despite the relative simplicity of mapping versus flowcharting, fully half of the students could not draw an accurate map. Common mistakes included laying out the map vertically, failing to label the arrows with documents, use of flowchart symbols and, most importantly, embellishments on the process described. Because of these results, another lecture period was devoted to process mapping and a large map was developed in class. An effort was made to help the students understand the necessity of mapping only what they knew to be true about an existing process, that it was important not to infer anything about an existing process. In the second examination a similar question was posed with most of the students being able to distinguish correctly between a process map and a flowchart. There were still, however, five students (approximately $12 \%$ ) who made the same mistakes as in the first examination.

More discouraging was the result of the major process map project. The process map project was assigned after the second examination results were known to the students (although the students were aware of the project from the first day of class). Part of a lecture period was spent going over requirements and printed instructions were provided to the students. Despite the emphasis on process mapping during the course and the results of the two examinations, nearly $20 \%$ of the students turned in a flowchart of the assigned process rather than a process map. Clearly, the exposure to the flowcharting material in the textbook had a profound effect on some of the students.

In addition to the process mapping content, more time was devoted to the transaction cycles and the cycles were always referred to as business processes or processes. At least two full lecture periods were devoted to each of the major processes (Revenue, Expenditure, Purchases, Inventory, and Payroll.) Coverage of each process included process controls, process interactions with other processes, process documents, 'Best Practices', and process implementation on an ERP. The intent of this coverage was to enable the students to make a mental link between 'normal' coverage of business processes and the actual implementation of that knowledge.

Coverage of the controls, interactions, documents and 'Best Practices' was provided using textbook reading assignments, printed handouts which provided material beyond the scope of the textbook (but commonly included in other AIS textbooks), and classroom lectures. Coverage of the process implementation on an ERP was provided using printed handouts, classroom lectures, and hands-on instruction/practice on Great Plains Dynamics and SAP R/3. The Great Plains project was assigned as a take-home assignment and was designed to ease the students into the ERP experience. Students purchased the Arens and Ward (1999) package and followed the instructions and assignments provided in the text. The students reported very little trouble completing the Great Plains assignment. Following the completion of their Great Plains project students were introduced to SAP R/3. The hands-on instruction/practice on SAP R/3 took up $20 \%$ of the class time and was a cause of frustration to most of the students according to an exit survey. Slower students thought the instruction was paced too fast, faster students thought the instruction was paced too slowly. Despite these frustrations, the majority of the students indicated on the exit survey 
Table 1. Results of exit survey of test AIS course

\begin{tabular}{|c|c|c|}
\hline Survey questions & $\begin{array}{l}\text { Number of } \\
\text { responses }\end{array}$ & $\begin{array}{l}\text { Per cent } \\
\ddot{n}=4 l\end{array}$ \\
\hline \multicolumn{3}{|l|}{ When the professor provides step-by step SAP Instruction in class: } \\
\hline I find it easy to follow the cursor & 21 & 51 \\
\hline I find it difficult to follow the cursor & 11 & 27 \\
\hline I find it nearly impossible to follow the cursor & 1 & 2 \\
\hline Non-respondent & 8 & 20 \\
\hline \multicolumn{3}{|l|}{ When the professor provides step-by-step SAP Instruction in class: } \\
\hline The professor moves through the fields too slowly & 1 & 2 \\
\hline The professor moves through the fields too fast & 12 & 29 \\
\hline The professor moves through the fields at just the right speed & 20 & 49 \\
\hline Non-respondents & 8 & 20 \\
\hline \multicolumn{3}{|l|}{ When I work on SAP in class (Choose all that apply)* } \\
\hline I get very tense and nervous & 3 & 7 \\
\hline I find it difficult to concentrate & 3 & 7 \\
\hline I enjoy it more than normal lecture/discussion & 22 & 54 \\
\hline $\begin{array}{l}\text { I want the professor to stand behind me and tell me exactly what } \\
\text { button to push next }\end{array}$ & 2 & 5 \\
\hline $\begin{array}{l}\text { I want other students to pay attention so that the class can move } \\
\text { more quickly }\end{array}$ & 7 & 17 \\
\hline $\begin{array}{l}\text { I wish we were grouped by ability so the class could move at my } \\
\text { pace }\end{array}$ & 6 & 15 \\
\hline Non-respondents & 2 & 5 \\
\hline \multicolumn{3}{|l|}{ When it comes to Great Plains, SAP and Business Processes: } \\
\hline I do not see the connection between the two software packages & 4 & 10 \\
\hline $\begin{array}{l}\text { I see the connection between GP and SAP but not the connection to } \\
\text { Business Processes }\end{array}$ & 2 & 5 \\
\hline $\begin{array}{l}\text { I see the connection between GP and SAP and Business Processes } \\
\text { but I don't see why I should care }\end{array}$ & 2 & 5 \\
\hline I see the connection between GP and SAP and Business Processes & 30 & 73 \\
\hline Non-respondent & 3 & 7 \\
\hline
\end{tabular}

* Per cent greater than $100 \%$ due to multiple responses

they thought they understood the connection between business processes and their exercises using Great Plains and SAP R/3. These results are presented in Table 1. It is clear that using ERP software to help teach business processes was effective with $73 \%$ of the students reporting they understood the connection between business processes. Slightly more than half the students (54\%) preferred working with the ERP software to normal lectures/discussion.

\section{Proposed business process courses}

In this section, is presented a plan for incorporating process maps and scripting in two business process courses named Entity Wide Business Processes and Advanced Entity Wide Business Processes. As the names imply, course content will focus on business 
processes. Because of the prevalent use of process mapping to evaluate the effectiveness of existing business processes, this tool will be used to discuss various processes and their interrelationships in the first course ${ }^{13}$ Scripting is scheduled to be a component in the second course. In addition, students will have hands-on experience with an ERP application in both courses.

Course content will address two of the eight components that comprise KPMG's BMP Client Business Model framework (Bell et al., 1997, pp. 34-38), which is reproduced in Figure 4. KPMG's BMP audit begins with a strategic analysis that focuses on understanding the client's missions and objectives and identifying the business risks. Their analysis takes a holistic perspective that includes identifying existing alliances, markets, and external forces. Along this line, given that corporate strategy defines the structure (business processes) that must be implemented to support the strategy, what KPMG refers to as the strategic management process and core business processes will be addressed, which are two of the three components of the business process analysis.

As illustrated in Figure 4, business processes are dependent on and support the strategic plan. Consequently, a company's strategic goals must first be identified. For example, for the year 2000, Amazon.com includes the following six major goals in its 1999 annual report letter to shareholders:

1. growth in both the number of our customers and the strength of the relationship we have with each of them;

2. continued rapid expansion of the products and services we offer;

3. driving operational excellence in all areas of the company;

4. international expansion;

5. expanding our partnership programs;

6. and last, importantly, driving toward profitability in each and every business we are in.

These six goals prescribe the processes Amazon.com must have in place in order to succeed. For example, in order to achieve its first goal, Amazon.com must have an efficient product delivery core process in position. Because our students may not have had exposure to business strategy, ${ }^{14}$ we believe we must touch on this topic. This will better prepare students to determine and evaluate the effectiveness of necessary core processes for a particular strategy and industry.

Approximately $20 \%$ of the first course will be devoted to learning about business processes. ${ }^{15}$ As an introduction to business systems, the students will be asked to arrange a list of core business processes in order of occurrence given a specific corporate strategy. This will accomplish several objectives. First is to create awareness of the complexity inherent in most organizations; the second is to demonstrate the interaction among various processes; and finally, to help students perceive the need to have a systematic way to describe the processes.

\footnotetext{
13 While we believe that flowcharting, DFDs, and REA modelling should be included in the AIS curriculum, given the nature of this course we introduce only the process mapping technique.

14 The required Business Strategy and Policy Seminar is a senior-level capstone course, which most students take in their final quarter.

${ }^{15}$ The course is taught in a quarter system; therefore it meets twice a week for ten weeks in one hour and fifty minute sessions.
} 


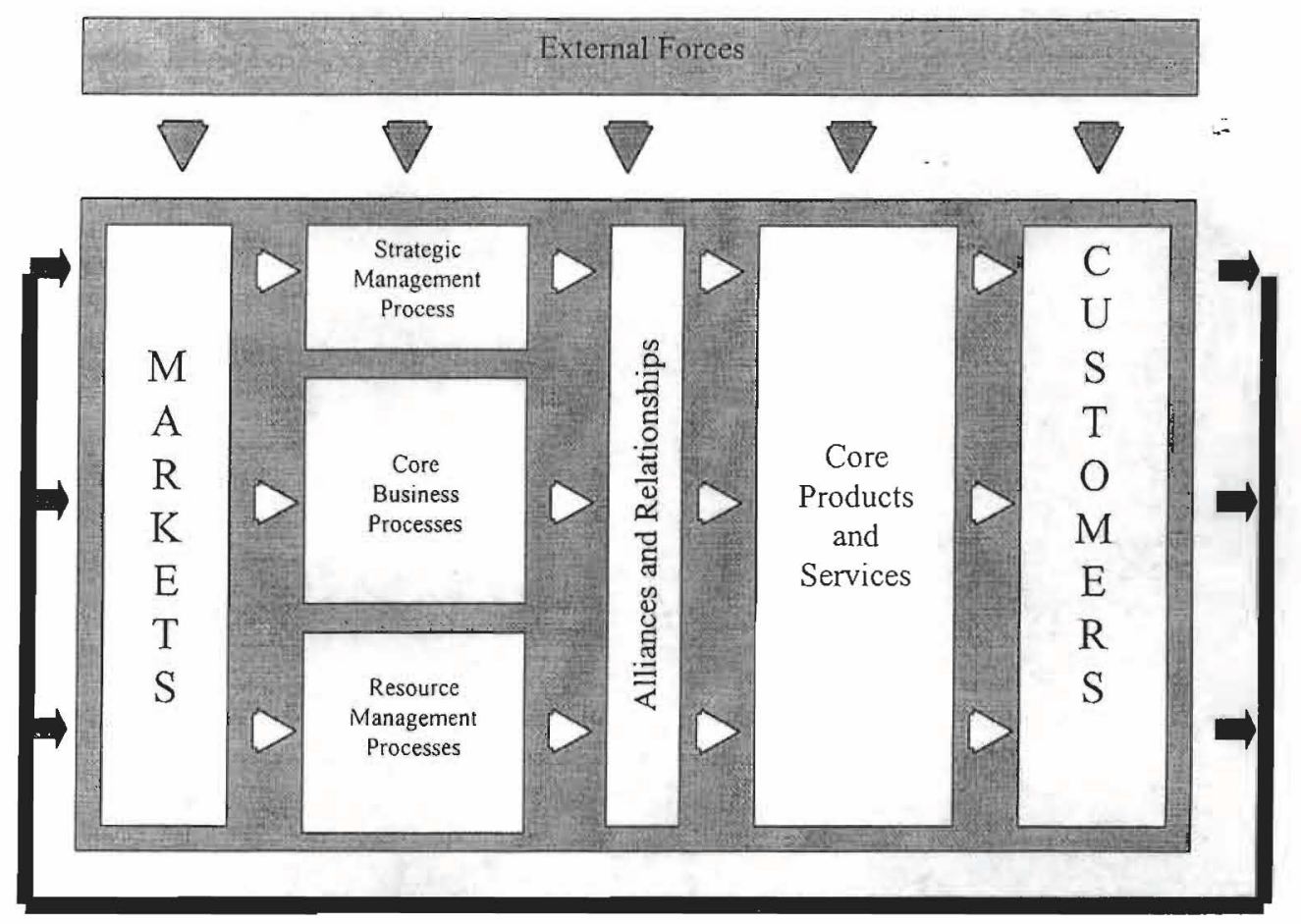

Fig. 4. KPMG client business model framework. Source: Auditing Organizations Through a Strategic-Systems Lens: The KPMG Business Measurement Process. Bell et al. (1997).

Based on the lessons learnt in the AIS class as discussed in the last section, we opted not to use an AIS textbook with a flowchart/transaction cycle perspective, which seemed to confuse students as they attempted to map a business process. Instead, we will use Why ERP by Jacobs and Whybark (2000), SAP R/3 Business Blueprint: Understanding Enterprise Supply Chain Management, by Curran and Ladd (1999), and The Basics of Process Mapping by Damelio (1996). To provide further guidance, students will be led through several exercises that require them to map simple processes using the mapping protocol as outlined in the process mapping and scripting section. A traditional problem on transaction cycles was adapted for process mapping exercises. The students will progress to analysing a large case where they will map the interrelationships among business processes (the 'as is' map), then suggest and map process improvement (the 'to be' map). Preparation of the 'as is' map helps students delineate what they know rather than what they infer about a system. The 'to be' map challenges them to critique current conditions and consider improvements.

Then a session will be included on techniques to use and questions that must be asked to evaluate and document an existing business process. An in-class activity will be to identify the core processes in a case; each team will then be assigned a given process to evaluate and map. Each team will be responsible for preparing a class presentation to summarize its analysis. The other teams will be required to report whether and how their process relates to the process being presented. 
Since the majority of students in the AIS course found the ERP software helpful when learning about business processes, and more than half the students $(54 \%)$ preferred working with the ERP software to normal lectures/discussion, ERP software will also be included in the proposed course. However, because of the frustration the student's expressed, the time required to teach a high-end ERP, lack of an installed ERP application in the current environment, and the inability to satisfy everyone with this kind of (what some would call training) instruction it was decided to use Smart Force's training CDs for SAP and SAP's Internet Demo and Evaluation System (IDES) project. ${ }^{16}$

The second course will delve deeper into business process analysis and will introduce scripting. Student teams will be required to locate a firm that will allow them to perform a process analysis. As they did with the case, both an 'as is' and a 'to be' process map will be required. The teams will also be required to prepare a script that would provide the information necessary to a programmer when implementing their 'to be' map. Because a script bridges the accountant's understanding of the business process and the programmer's implementation of that process on an ERP, by building a script the students have the opportunity to think about, and demonstrate their understanding of, the implementation of a process at the ERP level. Because even a small process can result in a very large, detailed script this also encourages students to actively think about the details involved in a business process. Because of time constraints, however, only a small subprocess will be scripted by the students.

\section{Summary and conclusion}

The accounting profession has recently seen two monographs in which the authors express their concern about the future and relevancy of accounting education. Albrecht and Sack (2000) believe that one of the reasons for the declining interest in accounting as a major has been accounting educators' 'unwillingness to prepare students for changing careers' (p. 31). In their survey, Albrecht and Sack found that $72.1 \%$ of faculty felt that accounting graduates would be more likely to be involved in planning and strategy and $88.9 \%$ of faculty believed demand would increase for accountants to be involved in business consulting and advising (p. 16). In an Institute of Management Accountants-funded study, the researchers found that management accountants believe 'strategic planning and process improvement are the two most critical work activities for the success of their companies' (Barth, 1999, p. 5). However, the interviewed respondents also believe the skills necessary to successfully contribute to these activities are rarely included in university accounting curricula. In the same study, respondents were asked to identify the most important knowledge, skills, and abilities. Understanding of how a business functions was ranked in the top five (p. 13) and process improvement was listed as one of the activities they spend more time performing now than they did five years ago (p. 17).

Given the skill-shift in the accounting profession and because of the widespread interest in process re-engineering, understanding business processes and being able to portray them on paper seems an important skill for accounting students to acquire. We believe that the use of process mapping in an AIS course will (1) help students grasp the cross-functional nature of most business processes and (2) better prepare students for what they will, in all

${ }^{16}$ These products are accessible at <http://www.smartforce.com/ > and <http://www.sap.com/ides > 
probability, be doing upon graduation - evaluating business processes in terms of risk and/ or in terms of suggesting improvement.

As has been illustrated, we found that process mapping and scripting are used in a variety of ways in practice. The goal was to describe the two tools and discuss how they are used during process re-engineering, as auditors evaluate business risk, and in an ERP application implementation. Because of their popularity and the focus of our two new Entity Wide Business Process courses, it is intended to include them as tools to help students understand and analyse business processes. An example of their use in a traditional AIS course has been presented. As mentioned, there were some confusing aspects associated with this first attempt, which is hoped will be alleviated as the Entity Wide Business Process courses are developed. Finally, plans for including process mapping and scripting in the two courses are presented. It is hoped that process mapping and scripting will help students appreciate the richness and complexity of business processes that exist in today's companies.

\section{Acknowledgements}

The authors would like to thank seminar participants at the AIS Educator Conference in Denver Colorado on 31 July-2 August 2000 and two anonymous reviewers of this journal for their helpful comments.

\section{References}

Albrecht W. and Sack, R. (2000) Accounting Education: Charting the Course through a Perilous Future. Sarasota, FL: American Accounting Association.

Aldowaisan, T. and Gaafar, L. (1999) Business process reengineering: an approach for process mapping. Omega, International Journal of Management Science 27, 515-24.

Arens, A. and Ward, D. (1999) Computerized Accounting Using Great Plains Dynamics. Okemos, MI: Armond Dalton Publishers.

Barth, C. (ed.) (1999) Counting More, Counting Less: Transformations in the Management Accounting Profession. Montvale, NJ: Institute of Management Accountants.

Bell, T., Marrs, F., Solomon, I. and Thomas, H. (1997) Auditing Organizations Through a StrategicSystems Lens: The KPMG Business Measurement Process. Montvale, NJ: KPMG Peat Marwick LLP.

Carr, D. and Johansson, H. (1995) Best Practices in Reengineering: What Works and What Doesn't in the Reengineering Process. New York: McGraw-Hill.

Curran, T. and Ladd, A. (1999) SAP R/3 Business Blueprint: Understanding Enterprise Supply Chain Management. Upper Saddle River, NJ: Prentice Hall.

Damelio, R. (1996) The Basics of Process Mapping. New York: Quality Resources.

Fulscher, J. and Powell, S. (1999) Anatomy of a process mapping workshop. Business Process Management Journal 5(3), 208-37.

Hall, J. (2000) Accounting Information Systems, 3rd edn. Cincinnati, Ohio: South-Western College Publishing.

Harrington, J. (1991) Business Process Improvement: The Breakthrough Strategy For Total Quality, Productivity, and Competitiveness. New York: McGraw-Hill.

Heagy, C., Nash, J. and Courtney, H. (1999) The Design, Selection, and Implementation of Accounting Information Systems, 4th edn. Houston, TX: Dame Publications.

Hiebeler, R., Kelly, T. and Ketteman, C. (1998) Best Practices: Building Your Business with Arthur Andersen's Global Best Practices. New York: Simon \& Schuster. 
Hollander, A., Denna, E. and Cherrington, J. (2000) Accounting Information Technology, and Business Solutions, 2nd edn. New York: Irwin McGraw-Hill.

Jacobs, F. and Whybark, D. Clay (2000) Why ERP: A Primer on SAP Implementation. New York: Irwin McGraw-Hill.

James, D. and Seibert, G. (1999) Oracle Financials Handbook: Planining and Implementing the Oracle Financial Applications Suite. Berkeley, CA: Osborne/McGraw Hill.

Keller, P. and Jacka, M. (1999) Process mapping. Internal Auditor 56(5), 60-64.

McCarthy, W. (1982) The REA accounting model: a generalized framework for accounting systems in a shared data environment. The Accounting Review 57(3), 554-78.

Romney, M. and Steinbart, P. (2000) Accounting Information Systems, 8th edn. Upper Saddle River, NJ: Prentice Hall.

Selander, J. and Cross, K. (1999) Process redesign: Is it worth it? Management Accounting 80(7), $40-44$.

Symons, R. and Jacobs, R. (1997) Multi-level process mapping: a tool for cross-functional quality analysis. Production and Inventory Management Journal 38(4), 71-76.

Wilkinson, J., Cerullo, M., Ramel, V. and Wong-on-Wing, B. (2000) Accounting Information Systems Essential Concepts and Applications, 4th edn. New York: John Wiley \& Sons.

Wisner, P. and Roth, H. (1998) Metalworks Company. Issues in Accounting Education 13(4), $1043-57$. 